ARTICLE

DOI: $10.1038 / \mathrm{s} 41467-017-00431-9$

\title{
Fast kinetics of magnesium monochloride cations in interlayer-expanded titanium disulfide for magnesium rechargeable batteries
}

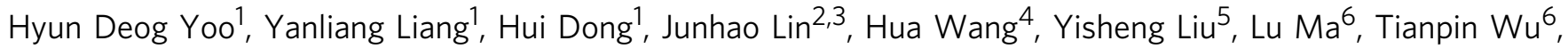

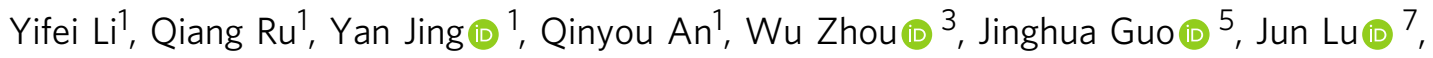

Sokrates T. Pantelides (10) ${ }^{2,3}$, Xiaofeng Qian ${ }^{4} \&$ Yan Yao (iD) ${ }^{1,8}$

Magnesium rechargeable batteries potentially offer high-energy density, safety, and low cost due to the ability to employ divalent, dendrite-free, and earth-abundant magnesium metal anode. Despite recent progress, further development remains stagnated mainly due to the sluggish scission of magnesium-chloride bond and slow diffusion of divalent magnesium cations in cathodes. Here we report a battery chemistry that utilizes magnesium monochloride cations in expanded titanium disulfide. Combined theoretical modeling, spectroscopic analysis, and electrochemical study reveal fast diffusion kinetics of magnesium monochloride cations without scission of magnesium-chloride bond. The battery demonstrates the reversible intercalation of 1 and 1.7 magnesium monochloride cations per titanium at 25 and $60^{\circ} \mathrm{C}$, respectively, corresponding to up to $400 \mathrm{mAh} \mathrm{g}^{-1}$ capacity based on the mass of titanium disulfide. The large capacity accompanies with excellent rate and cycling performances even at room temperature, opening up possibilities for a variety of effective intercalation hosts for multivalent-ion batteries.

\footnotetext{
${ }^{1}$ Department of Electrical and Computer Engineering \& Materials Science and Engineering Program, University of Houston, Houston, TX 77204, USA.

${ }^{2}$ Department of Physics and Astronomy, Vanderbilt University, Nashville, TN 37235, USA. ${ }^{3}$ Materials Science and Technology Division, Oak Ridge National Laboratory, Oak Ridge, TN 37831, USA. ${ }^{4}$ Department of Materials Science and Engineering, Texas A\&M University, College Station, TX 77843, USA.

${ }^{5}$ Advanced Light Source, Lawrence Berkeley National Laboratory, 1 Cyclotron Road, Berkeley, CA 94720, USA. ${ }^{6}$ X-Ray Science Division, Argonne National Laboratory, Lemont, IL 60565, USA. ${ }^{7}$ Chemical Sciences and Engineering Division, Argonne National Laboratory, Argonne, IL 60439, USA. ${ }^{8}$ Texas Center for Superconductivity, University of Houston, Houston, TX 77204, USA. Correspondence and requests for materials should be addressed to

Y.Y. (email: yyao4@uh.edu)
} 
$\mathrm{M}$ agnesium rechargeable batteries (MRBs) are emerging as an attractive candidate for energy storage in terms of safety ${ }^{1,2}$, energy density ${ }^{3}$, and scalability ${ }^{4}$ because magnesium metal has ideal properties as a battery anode: high capacity, low redox potential, dendrite-free deposition, and earthabundant resources. Since the first MRB prototyped by Aurbach et al. ${ }^{1}$, significant progress has been made in cathodes ${ }^{5-17}$, electrolytes $^{18-25}$, and anodes ${ }^{26-29}$. One critical challenge for MRBs is the development of $\mathrm{Mg}$ storage cathodes with higher capacity and operating voltage than Chevrel phase $\mathrm{Mo}_{6} \mathrm{~S}_{8}$ cathodes ${ }^{30}$, 31, which operate at ca. $1 \mathrm{~V}$ vs $\mathrm{Mg} / \mathrm{Mg}^{2+}$ with capacity of ca. $100 \mathrm{mAh} \mathrm{g}^{-1}$. Recently, Nazar et al. reported spinel $\mathrm{Ti}_{2} \mathrm{~S}_{4}$ and layered $\mathrm{TiS}_{2}$ cathodes with a specific capacity of 200 and $160 \mathrm{mAh} \mathrm{g}^{-1}$, respectively ${ }^{16,17}$; however, both cathodes were operated at elevated temperature (i.e., $60^{\circ} \mathrm{C}$ ) due to the kinetic limitations.

Two major factors limit the development of MRB intercalation cathodes at room temperature (Fig. 1a). First, as $\mathrm{MgCl}^{+}$is the major electroactive species in typical halide-based $\mathrm{Mg}$ electrolytes ${ }^{32-39}$, the $\mathrm{Mg}-\mathrm{Cl}$ bond needs to be broken to free up the intercalating $\mathrm{Mg}^{2+}$ species, which process requires a high activation energy $\left(E_{\mathrm{a}}\right)$ of at least $3 \mathrm{eV}^{37}$. Second, most Mg-ion cathodes studied so far suffer from sluggish $\mathrm{Mg}^{2+}$ diffusion because of the extremely high-energy barrier for $\mathrm{Mg}^{2+}$ migration in host materials 3,40 .

In this work, we report a $\mathrm{MRB}$ based on a $\mathrm{MgCl}^{+}$intercalation cathode, a $\mathrm{Mg}$ anode, and a standard chloride-based electrolyte. Moving from the divalent $\mathrm{Mg}^{2+}$ to the monovalent $\mathrm{MgCl}^{+}$as the charge carrier makes Mg-ions similar to one-electron-transfer alkaline metal ions where (1) only low-energy desolvation $\left(E_{\mathrm{a}} \sim\right.$ $0.8 \mathrm{eV})$ but not high-energy $\mathrm{Mg}-\mathrm{Cl}$ scission $\left(E_{\mathrm{a}}>3 \mathrm{eV}\right)$ is necessary before intercalation and (2) the polarization strength of the ion, and hence the ion diffusion energy barrier, is low (Fig. 1b). The new battery chemistry illustrated using interlayerexpanded titanium disulfide $\left(\mathrm{TiS}_{2}\right)$ cathode as an example demonstrates 1 and $1.7 \mathrm{MgCl}^{+}$intercalation per formula of $\mathrm{TiS}_{2}$ at 25 and $60^{\circ} \mathrm{C}$, respectively, corresponding to high reversible capacities of up to $400 \mathrm{mAh} \mathrm{g}^{-1}$ based on the mass of $\mathrm{TiS}_{2}$. The electrode kinetics is fast even at room temperature. The chemical nature of intercalation species is thoroughly investigated using a combination of theoretical calculations and various spectroscopic and electrochemical studies.

\section{Results}

Theoretical modeling for the diffusion of $\mathrm{MgCl}^{+}$vs $\mathrm{Mg}^{2+}$. Although the faster diffusion owing to the lower polarity of $\mathrm{MgCl}^{+} \mathrm{vs} \mathrm{Mg}^{2+}$ is expectable based on the predictably decreased polarization strength, computational studies provide quantitative information on the diffusivity as a function of interlayer distance and the chemical structure of the ions, as well as the extent of $\mathrm{TiS}_{2}$ expansion required for $\mathrm{Mg}^{2+}$ and $\mathrm{MgCl}^{+}$to achieve maximum diffusivities. The diffusion behavior of $\mathrm{Mg}^{2+} \mathrm{vs} \mathrm{MgCl}^{+}$in layered materials is studied using $\mathrm{TiS}_{2}$ as a model compound with firstprinciples calculations. The diffusion of $\mathrm{Mg}^{2+}$ in layered $\mathrm{TiS}_{2}$ and its sensitivity to the interlayer spacing $(c)$ have been extensively studied by previous theoretical modeling effort ${ }^{41}$, which clearly demonstrated a significant decrease of the migration barrier with increasing lattice expansion (i.e., from 5.7 to $6.3 \AA$ ). Herein, we study the effect of further expansion of $\mathrm{TiS}_{2}$ on the mobility of $\mathrm{Mg}^{2+}$ and $\mathrm{MgCl}^{+}$. As $c$ increases from 5.7 to $10.9 \AA$, the $\mathrm{Mg}^{2+}$ migration barrier reduces from 1.06 to $0.51 \mathrm{eV}$ (Fig. 2a, b) as a result of smaller total binding energy between $\mathrm{Mg}$ and $\mathrm{S}$ in $\mathrm{TiS}_{2}$, in excellent agreement with the previous work ${ }^{41}$. However, further expansion from $10.9 \AA$ could not reduce the barrier anymore (Fig. 2a and Supplementary Fig. 1). In contrast, when $\mathrm{MgCl}^{+}$is considered as the active diffusive species in the interlayerexpanded $\mathrm{TiS}_{2}(c=10.9 \AA)$, migration barrier could be drastically reduced to $0.18 \mathrm{eV}$. Assuming the standard Arrhenius expression $\left(D \propto \mathrm{e}^{-E_{a} / k T}\right)$, the barrier decrease from 0.51 to $0.18 \mathrm{eV}$ is equivalent to $4 \times 10^{5}$ times faster cation diffusion at room temperature.

To understand the striking difference between the migration barrier for $\mathrm{Mg}^{2+}$ and $\mathrm{MgCl}^{+}$, we studied the electron density difference for the above three scenarios (Fig. 2c): (a) $\mathrm{Mg@TiS}_{2}$ with $c=5.7 \AA$, (b) $\mathrm{Mg} @ \mathrm{TiS}_{2}$ with $c=10.9 \AA$, and (c) $\mathrm{MgCl} @ \mathrm{TiS}_{2}$ with $c=10.9 \AA$. In the case of (a), with $\mathrm{Mg}$ initially bonded with both top and bottom $\mathrm{TiS}_{2}$ layers, electrons of $\mathrm{TiS}_{2}$ were largely polarized toward $\mathrm{Mg}$ with notable amount accumulated around the six neighboring $\mathrm{S}$ atoms. In the case of (b), the coordination number of $\mathrm{Mg}$ reduces from six to three, causing a net reduction in the electrostatic interaction. Although the electron density around the three neighboring $S$ atoms increases (manifested by the slightly enlarged orange lobes), the net migration energy barrier is reduced because of the decrease in the coordination

b

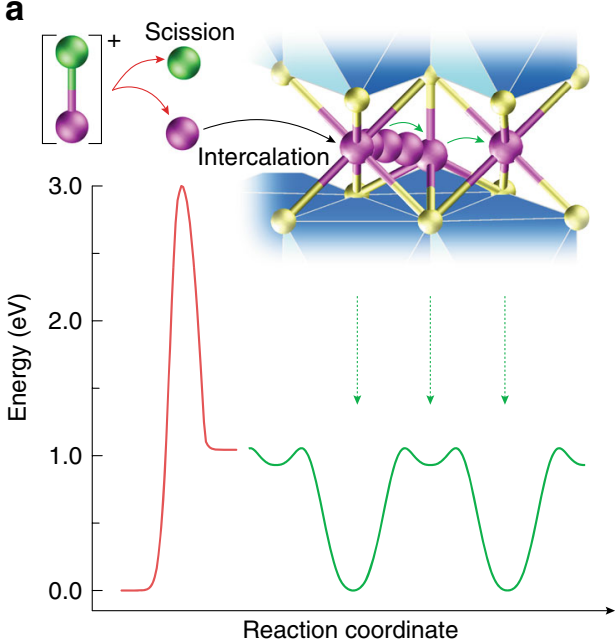

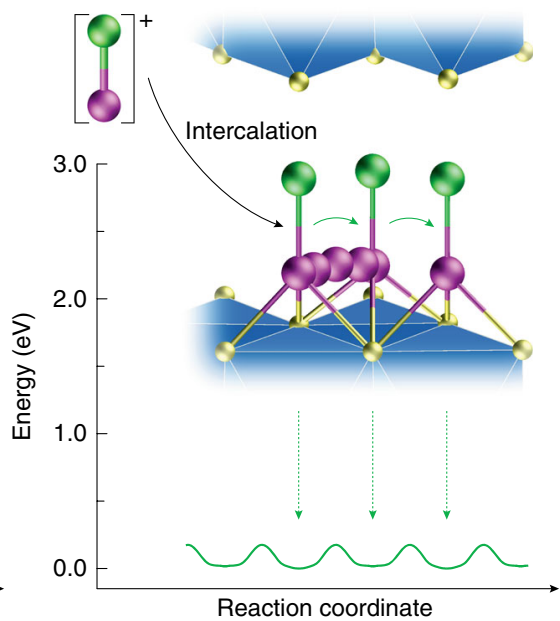

Fig. 1 Energy diagrams for the intercalation and diffusion of $\mathrm{Mg}^{2+}$ and $\mathrm{MgCl}^{+}$. a Typical intercalation of $\mathrm{Mg}^{2+}$ involves scission of $\mathrm{MgCl}^{+}$ions into $\mathrm{Mg}^{2+}$ and $\mathrm{Cl}^{-}$, which requires substantial activation energy of $3 \mathrm{eV}$ at least. Subsequent diffusion of divalent $\mathrm{Mg}^{2+}$ also has a high-migration energy barrier of $1.06 \mathrm{eV}$, which results in the limited level of intercalation at room temperature. $\mathbf{b}$ Intercalation of $\mathrm{MgCl}^{+}$bypasses the sluggish scission of the $\mathrm{Mg}-\mathrm{Cl}$ bond at the electrolyte-cathode interface; afterwards $\mathrm{MgCl}^{+}$diffuses fast in the expanded interlayers due to the fairly low-migration energy barrier of $0.18 \mathrm{eV}$. $\mathrm{Mg}$ and $\mathrm{Cl}$ atoms are shown as purple and green spheres, respectively 
a

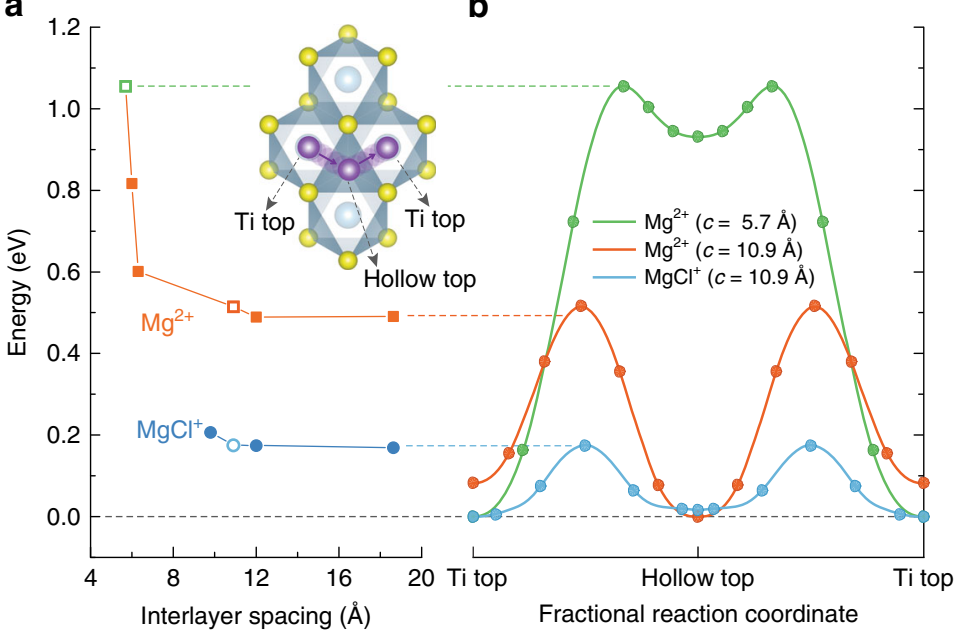

c
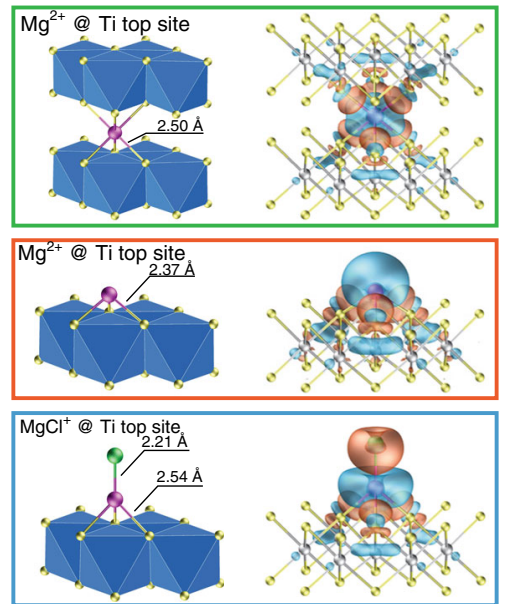

Fig. 2 First-principles calculations for the diffusion of $\mathrm{Mg}$-ions in $\mathrm{TiS}_{2}$. a Energy barrier for the migration of $\mathrm{Mg}^{2+}$ and $\mathrm{MgCl}^{+}$as a function of the interlayer distance of $\mathrm{TiS}_{2}$ at the dilute limit. The diffusion path from a Ti top to another Ti top site via the adjacent Hollow top site is shown in the inset. $\mathbf{b}$ Energy diagrams along the diffusion path for the three representative cases of $\mathrm{Mg}^{2+}$ at $c=5.7 \AA$ (green), $\mathrm{Mg}^{2+}$ at $c=10.9 \AA$ (orange), and $\mathrm{MgCl}{ }^{+}$at $c=10.9 \AA$ (cyan). c Atomic configurations of $\mathrm{Mg}^{2+}$ and $\mathrm{MgCl}^{+}$at Ti top site for the three cases in $\mathbf{b}$. The right panels show the charge difference plots constructed by subtracting the valence electron density of individual $\mathrm{Mg}$ atom, $\mathrm{Cl}$ atom, and $\mathrm{TiS}_{2}$ layers from that of $\mathrm{Mg} @ \mathrm{TiS}_{2}$ or $\mathrm{MgCl} @ \mathrm{TiS}_{2}$.Blue and orange colors represent depletion and accumulation of electron, respectively

number. In the case of (c), the bonding of the negatively charged $\mathrm{Cl}$ to $\mathrm{Mg}$ makes the electrons of $\mathrm{TiS}_{2}$ less polarized toward $\mathrm{Mg}$, as is indicated by shrunk orange lobes around the three coordinating $\mathrm{S}$ atoms. As a result, the strength of the three $\mathrm{Mg}-\mathrm{S}$ bonds reduces, as is indicated by the increase in the $\mathrm{Mg}-\mathrm{S}$ bond length from $2.37 \AA$ to $2.54 \AA$. The reduced strength of $\mathrm{Mg}-\mathrm{S}$ bonds leads to much smaller migration energy barrier. These results demonstrate that the marked reduction of migration barrier comes from two equally important factors: the increase of interlayer distance and the chemical structure of diffusive species involved in the migration process. It is worth noting that, without the expansion of $\mathrm{TiS}_{2}$, neither the intercalation nor the fast diffusion of $\mathrm{MgCl}^{+}$would be possible. This simulation motivates us to find a method to expand the interlayer spacing to accommodate $\mathrm{MgCl}$-ions.

In situ expansion of $\mathrm{TiS}_{2}$ in $\mathbf{M g}$ battery cells. In most cases, layered materials are expanded ex situ ${ }^{42-44}$, i.e., by mechanical or chemical processes before they are introduced in a battery. However, moisture-sensitive $\mathrm{TiS}_{2}$ is prone to oxidation during the ex situ processes and subsequent cell fabrication. It has been reported that intercalation of organic compounds can expand layered materials in a highly controllable manner without exfoliating the structure into single layers ${ }^{45-47}$. We chose the chemically stable 1-butyl-1-methylpyrrolidinium ion $\left(\mathrm{PY}_{1} 4^{+}\right)$as an organic "pillar" 48,49 , which expands $\mathrm{TiS}_{2}$ layers in situ, i.e., by discharging a complete $\mathrm{TiS}_{2} / \mathrm{Mg}$ cell using the electrolyte containing PY $14^{+}$ions. The reversible Mg deposition and dissolution in the electrolyte solution is not hampered with the addition of the PY14 ${ }^{+}$ions (Supplementary Table 1 and Supplementary Fig. 2).

In operando X-ray diffraction (XRD) shed light on the structural evolution of $\mathrm{TiS}_{2}$ during the initial activation of the cell (Fig. 3a and Supplementary Fig. 3). The as-fabricated electrode (stage 0 ) shows a peak at $15.56^{\circ}$, corresponding to the (001) plane of pristine $\mathrm{TiS}_{2}$ with $c=5.69 \AA$. After discharging to $1 \mathrm{~V}$ vs $\mathrm{Mg} / \mathrm{Mg}^{2+}$ (stage 1 ), new peaks evolve at $8.13^{\circ}$ and $16.31^{\circ}$, corresponding to (001) and (002) planes with $c=10.87 \AA$. Further discharging to $0.2 \mathrm{~V}$ vs $\mathrm{Mg} / \mathrm{Mg}^{2+}$ (stage 2) results in four new peaks at $4.74^{\circ}, 9.49^{\circ}, 14.26^{\circ}$, and $19.04^{\circ}$, corresponding to (001) to
(004) planes with $c=18.63 \AA$ (Supplementary Table 2). The shifts of diffraction peaks from stage 0 to 1 and from stage 1 to 2 are irreversible (Supplementary Fig. 4). And the expanded interlayer spacing is maintained same as that of stage 2 upon subsequent stages of discharge/charge cycling. Deeper discharging to $0 \mathrm{~V}$ vs $\mathrm{Mg} / \mathrm{Mg}^{2+}$ (stage 3) does not further shift the peaks but the peak intensities become attenuated, suggesting a structural disorder as evidenced by intralayer ruptures in the scanning transmission electron microscopy (STEM) image at stage 3 (Fig. 3b). The interlayer spacing from the STEM image for each stage is in excellent agreement with the value from XRD.

High-energy X-ray diffraction (HE-XRD) confirms the interlayer distance in Supplementary Table 2 with higher resolution (Fig. 3c). Moreover, the HE-XRD patterns at four stages show that (100) and (110) peaks, solely related with $a b$-plane, do not shift, indicating the intralayer structure of $\mathrm{TiS}_{2}$ is preserved during expansion along the $c$-direction. Cross-sectional elemental mapping at stage 4 shows alternating layers of $\mathrm{Ti}$ and $\mathrm{C}$, which is a clear evidence that organic PY14+ "pillars" stay in the van der Waals gap of $\mathrm{TiS}_{2}$ after discharge (Fig. 3d). The expanded $\mathrm{TiS}_{2}$, or exTiS $_{2}$, remains compact without exfoliation during the cycling (Supplementary Fig. 5). The initial activation is complete at this stage with PY $14^{+}$contributing a one-time irreversible capacity of $\sim 50 \mathrm{mAh} \mathrm{g}^{-1}$. And PY $14^{+}$does not contribute to the reversible capacity in the following cycles.

Chemical nature of exTiS ${ }_{2}$ at each stage of intercalation. We conducted detailed characterizations of samples prepared at different stages. First, intercalating species at each stage was investigated using energy dispersive spectroscopy (EDS), inductively coupled plasma optical emission spectrometry (ICP-OES), and Xray photoelectron spectroscopy (XPS). Although negligible $\mathrm{Mg}$ and $\mathrm{Cl}$ signals were detected at stage 1 (Fig. $4 \mathrm{a}, \mathrm{b}$ ), strong $\mathrm{N} 1 \mathrm{~s}$ peak in the XPS spectrum confirms that only PY $14^{+}$ions intercalate during stage 0 to 1 (Fig. 4a). Signals for $\mathrm{Mg}$ and $\mathrm{Cl}$ atoms increase substantially when further discharging to stages 2 and 3 ; and both signals decrease when charging back to stage 4 (Fig. 4a, b and Supplementary Table 3). The atomic ratio of Mg to Ti reaches $1 \pm 0.1$ at stage 3 according to ICP-OES, whereas the atomic ratio of $\mathrm{Mg}$ to $\mathrm{Cl}$ is $1 \pm 0.2$ at each stage according to EDS 
a

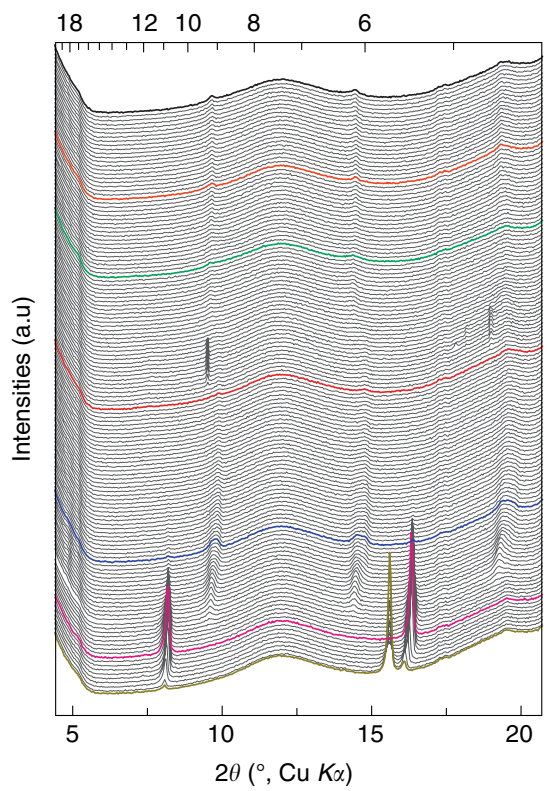

b

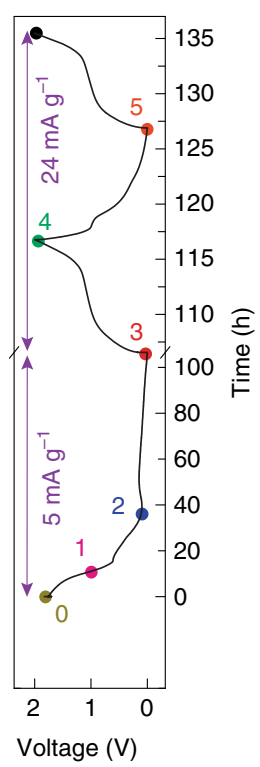

d

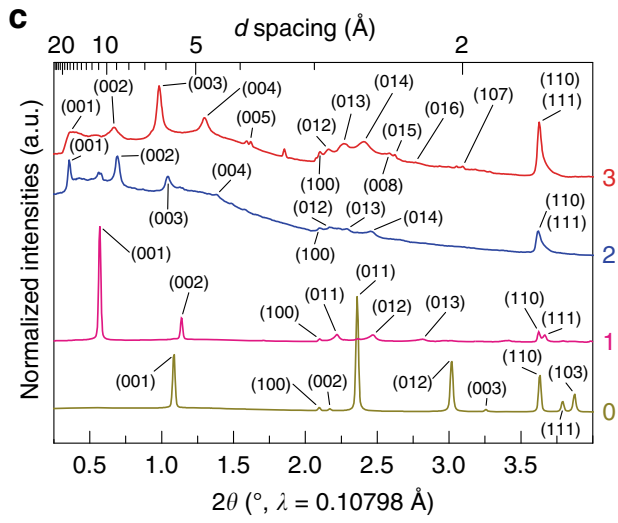

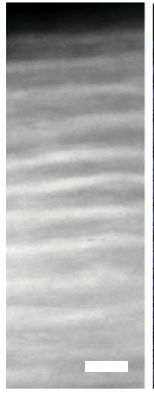

Image

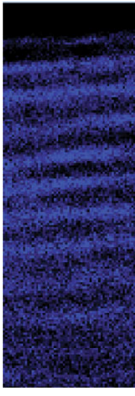

$\mathrm{Ti}$

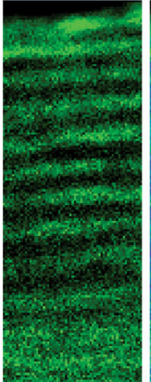

C

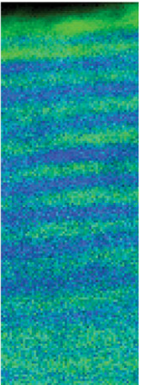

$\mathrm{Ti}+\mathrm{C}$

Fig. 3 Structural characterizations of $\mathrm{TiS}_{2}$ during the initial activation. a In operando XRD characterization and corresponding galvanostatic voltage profile for the first two cycles. b STEM images for stages 0 to 4. $\mathbf{c}$ HE-XRD patterns for stages 0 to 3. $\mathbf{d}$ The STEM image and the elemental mapping of Ti and $\mathrm{C}$ at stage 4. Scale bars: $2 \mathrm{~nm}$

(Supplementary Table 3). Electron energy loss spectroscopy (EELS) also evidences $\mathrm{Mg}$ and $\mathrm{Cl} \mathrm{L}_{2,3}$ peaks for stage 3, whereas the peaks are absent at stage 4 (Fig. 4c). Both discharged and charged electrodes (stages 3 and 4 , respectively) contain $\sim 1$ at.\% of $\mathrm{Al}$, which most likely originated from $\mathrm{AlPh}_{2} \mathrm{Cl}_{2}{ }^{-}$anions adsorbed on the surface (Fig. 4b). Proton nuclear magnetic resonance $\left({ }^{1} \mathrm{H}-\mathrm{NMR}\right)$ spectroscopy detected small amount of tetrahydrofuran (THF) from stages 2 to 4 , suggesting possible solvent co-intercalation in exTiS 2 (Supplementary Fig. 6). The number of THF molecule in the fully discharged sample $(\sim 0.16$ per $\mathrm{MgCl}^{+}$) is far lower than what is typically needed for the solvation of $\mathrm{MgCl}^{+}$ions (e.g., 3 in $[\mathrm{MgCl} \cdot 3 \mathrm{THF}]^{+}$). Combining these results and thermogravimetric analysis (Supplementary Fig. 7 and Supplementary Table 4), we obtain the composition of the discharged compound at stage 3 as $(\mathrm{MgCl})_{1.0} \mathrm{TiS}_{2}\left[(\mathrm{PY} 14)_{0.20}(\mathrm{THF})_{0.16}\right]$.

Second, near-edge X-ray absorption fine structure (NEXAFS) of $\mathrm{Mg} \mathrm{K}$-edge reveals the coordination state of the inserted $\mathrm{MgCl}-$ ions (Fig. 4d). Recent experimental and theoretical works showed that at least $1 \mathrm{eV}$ lower onset of X-ray absorption for tetracoordinated Mg-ions (e.g., $\quad\left[\mathrm{Mg}_{2} \mathrm{Cl}_{2} \cdot 4 \mathrm{THF}\right]^{2+}$ or $[\mathrm{MgCl} \cdot 3 \mathrm{THF}]^{+}$) compared with the hexacoordinated Mg-ions (e.g., $\left.\left[\mathrm{Mg}_{2} \mathrm{Cl}_{3} \cdot 6 \mathrm{THF}\right]^{+}\right)^{33}, 50,51$. The onset energy for the magnesiated $\mathrm{TiS}_{2}$ at stage 3 is closest to that of the tetracoordinated $\left[\mathrm{Mg}_{2} \mathrm{Cl}_{2} \cdot 4 \mathrm{THF}\right]^{2+50}$. Therefore, the intercalated $\mathrm{MgCl}$-ions maintain tetracoordination of $\mathrm{Mg}$ with $1 \mathrm{Cl}$ and $3 \mathrm{~S}$ atoms as predicted in Fig. 2c.

Last, to probe the sulfur coordination environment change upon $\mathrm{MgCl}^{+}$intercalation, $\mathrm{S}$ K-edge NEXAFS was performed on $(\mathrm{MgCl})_{x} \mathrm{TiS}_{2}$ for $x=0,0.5$, and 1 . The NEXAFS spectra are displayed in Fig. 4e after background subtraction and normalization. Three $\mathrm{S} K$-edge peaks $C, C^{\prime}$, and $D$ represent the transitions from $S 1 s$ to $S 3 p$ orbitals. The $C$ and $C^{\prime}$ peaks can be assigned to $t_{2 g}$ and $e_{g}$ states from the hybridization of $\mathrm{S} 3 p$ and $\mathrm{Ti}$ $3 d$ orbitals via $\pi^{*}$ and $\sigma^{*}$ antibonding, respectively. The intensity and width of $C$ and $C^{\prime}$ peaks decrease upon $\mathrm{MgCl}^{+}$intercalation, whereas peak $C$ exhibits more pronounced decrease in the intensity than $C^{\prime}$; but no noticeable energy shift is observed for the two peaks. Peak $D$, which can be assigned to hybridized S $3 p$ and $\mathrm{Ti} 4 s$ and $4 p$ orbitals, shows a progressive shift toward lower energy and an increase in the intensity upon $\mathrm{MgCl}^{+}$intercalation. The observed spectral changes are similar to the experimental and theoretical study for $\mathrm{Li}^{+}$intercalation into $\mathrm{TiS}_{2}{ }^{52}$, in which the reduced intensity of $C$ and $C^{\prime}$ peaks was originated from the structural distortion, with more pronounced influence on peak $C$ due to the partial filling of the $t_{2 g}$ states by the charge transfer 
a

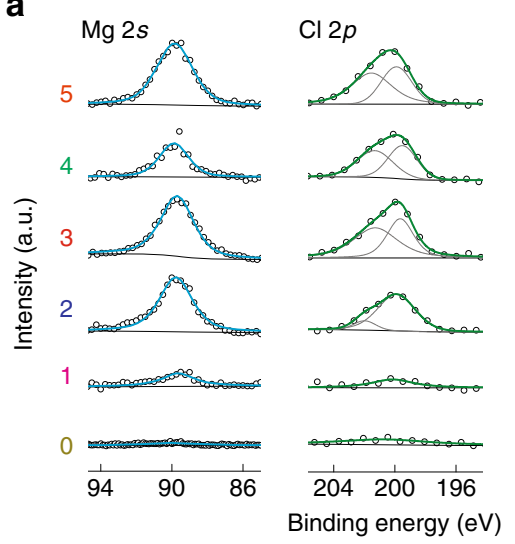

C

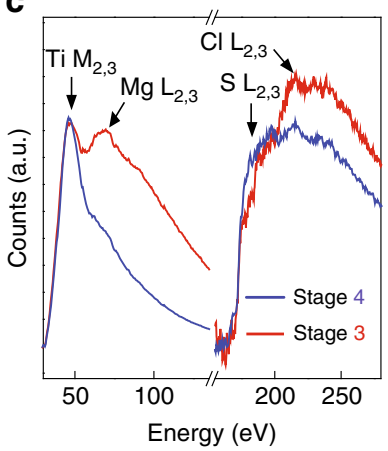

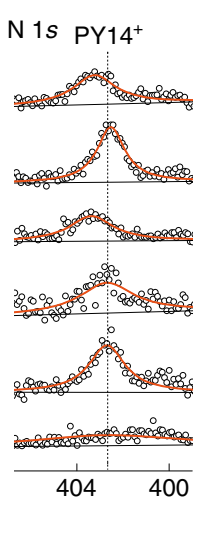

d

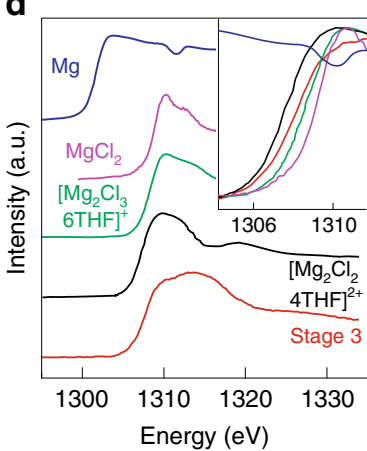

b

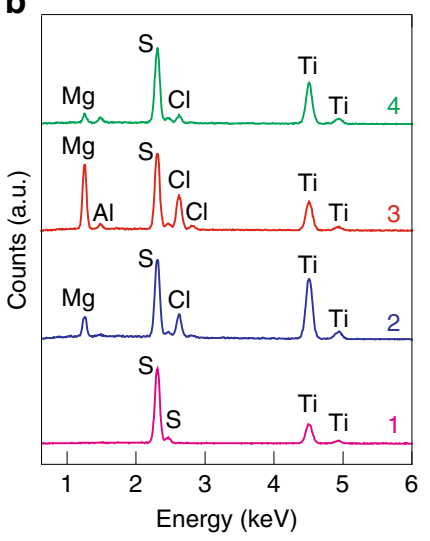

e

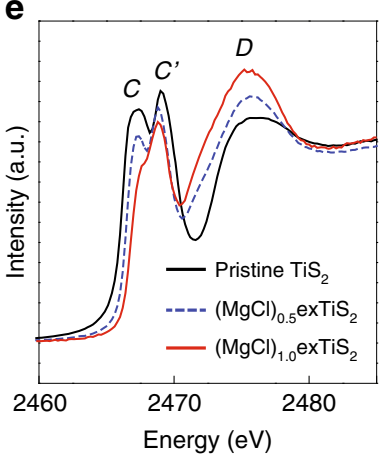

Fig. 4 Chemical nature of the intercalation compound at each stage. a XPS spectra of $\mathrm{Mg} 2 s, \mathrm{Cl} 2 p$, and N 1s for stages 0 to 5 . $\mathbf{b}$ EDS spectra for stages 1 to 4 . c EELS spectra at stages 3 and 4. d Mg K-edge NEXAFS spectra of $\mathrm{Mg}$ metal, $\mathrm{MgCl}_{2}$ powder, $\left[\mathrm{Mg}_{2} \mathrm{Cl}_{2} \cdot 4 \mathrm{THF}^{2+}\left(\mathrm{Nakayama}\right.\right.$ et al. $\left.{ }^{50}\right)$, $\left[\mathrm{Mg}{ }_{2} \mathrm{Cl} \mathrm{l}_{3} \cdot 6 \mathrm{THF}\right]^{+}$ (Benmayza et al. ${ }^{51}$ ), and magnesiated exTiS 2 at stage 3. e Experimental S $K$-edge NEXAFS spectra for $\mathrm{TiS}_{2}\left(\right.$ black), $\left(\mathrm{MgCl}_{0.5}\right.$ exTiS $\mathrm{S}_{2}($ blue, dashed), and $(\mathrm{MgCl})_{1.0} \mathrm{exTiS}_{2}($ red $)$

upon intercalation of ions. In our case, the structural distortion and charge transfer would be results from the $\mathrm{MgCl}^{+}$intercalation. The change of peak $D$ may reflect the bonding between $\mathrm{Mg}$ and $S$ atoms and the coordination number of $S$ changes from three in $\mathrm{TiS}_{2}$ to six in $(\mathrm{MgCl})_{x}$ exTiS ${ }_{2}$, whereby the hybridization of $\mathrm{S}$ increases.

Electrochemical performances of $\mathrm{exTiS}_{2} / \mathrm{Mg}$ battery cells. exTiS $_{2}$ shows a highly reversible capacity of $239 \mathrm{mAh} \mathrm{g}^{-1}$ based on the mass of $\mathrm{TiS}_{2}$ at the current density of $24 \mathrm{~mA} \mathrm{~g}_{\mathrm{TiS}_{2}}{ }^{-1}(0.1 \mathrm{C}$ rate), or $173 \mathrm{mAh} \mathrm{g}^{-1}$ based on the composite mass of $\mathrm{TiS}_{2}\left[(\mathrm{PY} 14)_{0.20}(\mathrm{THF})_{0.16}\right]$ at room temperature (Fig. 5a). Overall, $70 \%$ of the capacity can be maintained $\left(179 \mathrm{mAh} \mathrm{g}_{\mathrm{TiS}_{2}}{ }^{-1}\right)$ at a much higher current of $240 \mathrm{~mA} \mathrm{~g}^{-1}$ (1C). The capacity of 239 mAh g ${ }^{-1}$ corresponds to $1 \mathrm{MgCl}^{+}$per formula of $\mathrm{TiS}_{2}$, which is in accordance with the atomic ratio of 1 for $\mathrm{Mg} / \mathrm{Ti}$ and $\mathrm{Mg} / \mathrm{Cl}$ from ICP-OES and EDS measurements, respectively. The capacity values are higher than that of state-of-the-art cathodes operated at room temperature: e.g., Chevrel phase $\mathrm{Mo}_{6} \mathrm{~S}_{8}\left(95 \mathrm{mAh} \mathrm{g}^{-1}\right.$ at $0.1 \mathrm{C})^{53}$, thiospinel $\mathrm{Ti}_{2} \mathrm{~S}_{4}\left(130 \mathrm{mAh} \mathrm{g}^{-1} \text { at } 0.02 \mathrm{C}\right)^{16}$, and layered $\mathrm{TiSe}_{2}\left(110 \mathrm{mAh} \mathrm{g}^{-1} \text { at } 0.05 \mathrm{C}\right)^{11}$. The volumetric capacity of exTiS $_{2}$ is $235 \mathrm{Ah} \mathrm{L}^{-1}$, which is 3.6 times as high as that of pristine $\mathrm{TiS}_{2}\left(66 \mathrm{Ah} \mathrm{L}^{-1}\right)$ but $55 \%$ lower than that of $\mathrm{Mo}_{6} \mathrm{~S}_{8}\left(519 \mathrm{Ah} \mathrm{L}^{-1}\right)$ due to the decreased density caused by the volume expansion (Supplementary Table 5). The sloping shape of the discharging voltage profiles suggest formation of $(\mathrm{MgCl})_{x} \mathrm{exTiS}_{2}$ solid solution. This sloping shape agrees with the theoretical calculation for $\mathrm{Mg}^{2+}$ intercalation into layered $\mathrm{TiS}_{2}{ }^{41}$, but the voltage is lower than the calculated value probably because the interlayer expansion weakens the intercalation energy ${ }^{54}$. In terms of cycling stability, the exTiS ${ }_{2}$ electrode exhibits $80 \%$ capacity retention after 400 cycles at 1C-rate with coulombic efficiency consistently higher than $99 \%$ (Fig. 5b).

To confirm the mechanism is indeed intercalation rather than surface adsorption, cyclic voltammetry (CV) was measured at scan rates $(v)$ from 0.1 to $10 \mathrm{mV} \mathrm{s}^{-1}$ (Supplementary Fig. 8). Figure $5 \mathrm{c}$ shows the linear relationship between peak current vs $v^{1 / 2}$, indicating the mechanism is indeed diffusion-limited intercalation rather than surface-limited adsorption. Electrochemical impedance spectroscopy (EIS) was measured to check the capacitance at stages $0-3$. The significant increase in capacitance at stage 3 can be interpreted as the larger interfacial area compared to stages $0-2$, which may be related to the intralayer ruptures at stage 3 (Supplementary Fig. 9). However, the capacitance of $60 \mathrm{~F} \mathrm{~g}^{-1}$ corresponds to the capacity of ca. 33 $\mathrm{mAh} \mathrm{g}^{-1}$, which is only $14 \%$ of the total capacity. Such observation also supports the conclusion that most of the capacity comes from intercalation rather than adsorption.

To exclude the effect of PY $14^{+}$ions in the electrolyte on electrochemical performance of $\mathrm{exTiS}_{2}$, the electrode at stage 4 (i.e., completely deintercalated one) was transferred into a new cell with standard APC electrolyte solution without PY $14^{+}$ (Supplementary Fig. 10). The performance is largely retained with the reversible capacity of about $200 \mathrm{mAh} \mathrm{g}^{-1}$, which is 10 times larger than the capacity before the expansion. The decrease in capacity compared with the original cell is most likely due to the inevitable material loss during the thorough washing step before transferring to the new cell. This result confirms that the electrochemical performances of exTiS ${ }_{2}$ come from (de)intercalation of $\mathrm{MgCl}^{+}$and are independent of $\mathrm{PY} 14^{+}$ions in the electrolyte. Supplementary Fig. 11 shows stable cycling of $80 \%$ 
a

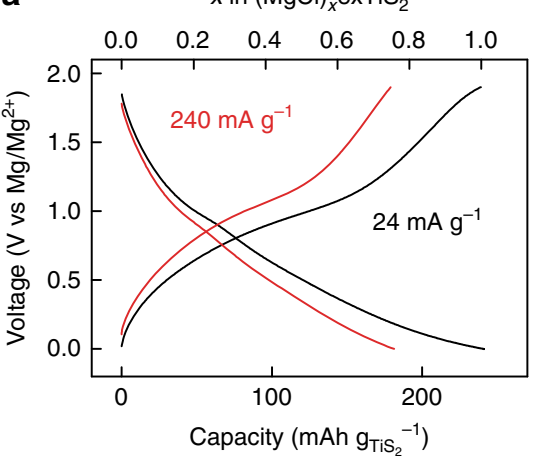

C

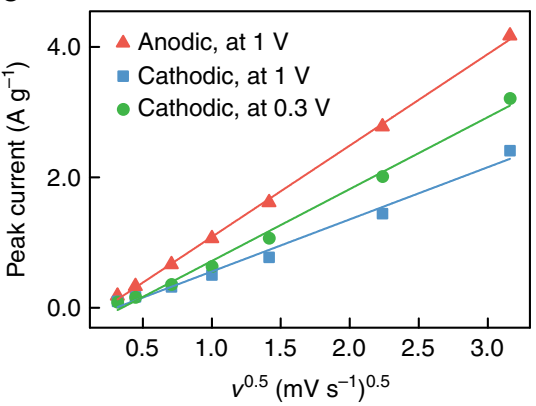

e

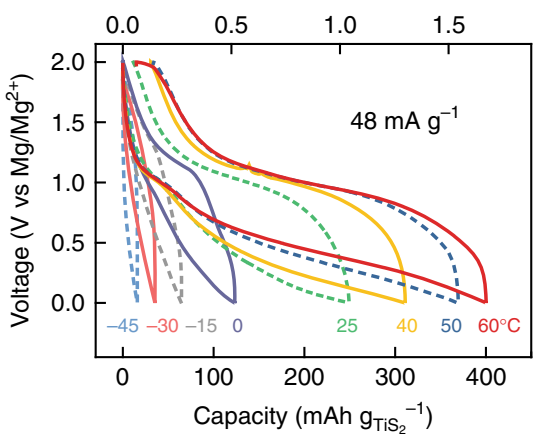

b

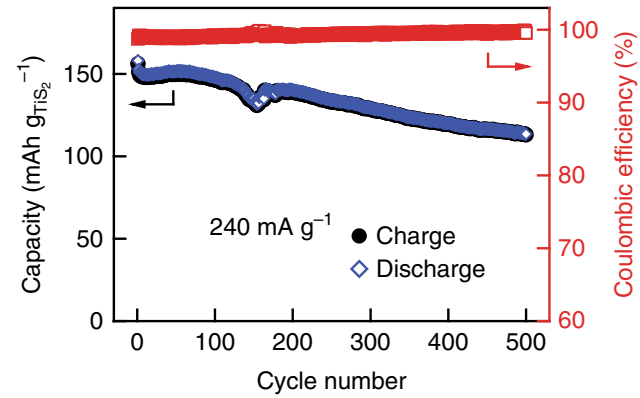

d

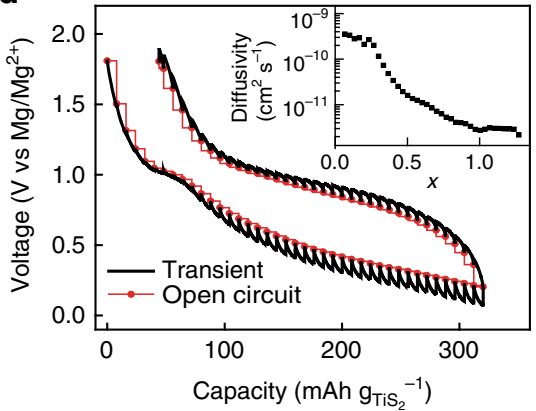

f

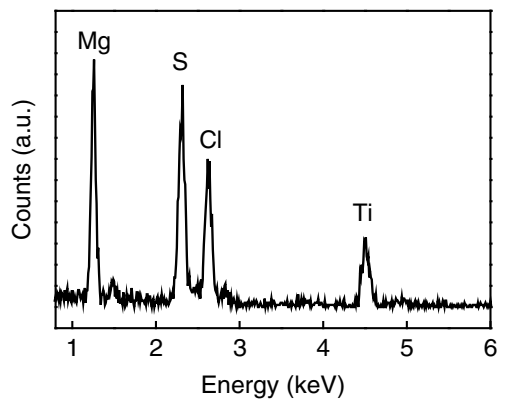

Fig. 5 Electrochemical performances of exTiS 2 . a Galvanostatic voltage profiles of the exTiS 2 electrode at 24 and $240 \mathrm{~mA} \mathrm{~g}^{-1}$ at $25^{\circ} \mathrm{C}$. The number of $\mathrm{MgCl}^{+}$intercalation per exTiS 2 is also shown in the top axis. $\mathbf{b}$ Cycling performance at $1 \mathrm{C}$-rate (i.e., $240 \mathrm{~mA} \mathrm{~g}^{-1}$ ). The capacity dip at the 150 th cycle is due to temperature change caused by temporary failure of air conditioner. $\mathbf{c} A$ linear relationship between the peak current in the cyclic voltammogram and the square root of the scan rate $(v)$. d GITT curve of an exTiS 2 electrode. e Voltage profiles of exTiS $S_{2}$ electrodes at temperatures varied from -45 to $60{ }^{\circ} \mathrm{C}$ at $48 \mathrm{~mA} \mathrm{~g}^{-1}$. $\mathrm{EDS}$ spectra for exTiS 2 discharged at $60^{\circ} \mathrm{C}$. Specific capacity is calculated based on the mass of $\mathrm{TiS}_{2}$

capacity retention after 350 cycles, similar to the cyclability observed in the PY14+-containing electrolyte. This result reaffirms that the organic cations are chemically stable and sufficiently immobile and stay in the structure with no change during the cycling.

Galvanostatic intermittent titration technique (GITT) was used to probe the reaction mechanism and determine the diffusivity of $\mathrm{MgCl}^{+}$in exTiS 2 as a function of depth-of-discharge (Fig. 5d) ${ }^{55}$. The open circuit potential (denoted as red) during the cycling corresponds to the true thermodynamic voltage profile. There is a voltage gap between charge and discharge, reflecting a $\mathrm{MgCl}^{+}(\mathrm{de})$ intercalation mechanism that involves the redistribution of a second mobile yet much more sluggish species, e.g., PY14 ${ }^{+}$, in the interlayer ${ }^{56}$. The diffusivity calculated during discharge is initially high at the level of $3 \times 10^{-10} \mathrm{~cm}^{2} \mathrm{~s}^{-1}$ but decreases with increasing $\mathrm{MgCl}^{+}$concentration and then stays constant as $3 \times 10^{-12} \mathrm{~cm}^{2} \mathrm{~s}^{-1}$ towards the end of discharging process (inset of Fig. $5 \mathrm{~d}$ ). The decrease in the diffusivity with increasing $\mathrm{MgCl}^{+}$concentration can be due to a divacancy diffusion mechanism as is well known to occur in $\mathrm{Li}^{+}$intercalation compounds ${ }^{57}$. The average $\mathrm{MgCl}^{+}$ diffusivity of $10^{-11} \mathrm{~cm}^{2} \mathrm{~s}^{-1}$ is one order of magnitude higher than that of $\mathrm{Mg}^{2+}$ in poly(ethylene oxide)-intercalated $\mathrm{MoS}_{2}{ }^{58}$ and Chevrel phase $\mathrm{Mo}_{6} \mathrm{~S}_{8}{ }^{59}$. The fast kinetics of $\mathrm{MgCl}^{+}$diffusion in exTiS $\mathrm{T}_{2}$ agrees with the simulation results. The high diffusivity of $\mathrm{MgCl}^{+}$ions in exTiS 2 interlayers enables the larger specific capacity and higher rate capability compared to other $\mathrm{Mg}^{2+}$ intercalation hosts reported at room temperature.

Finally, the effects of temperature on $\mathrm{exTiS}_{2} / \mathrm{Mg}$ cells were studied. As the temperature increased from -45 to $60^{\circ} \mathrm{C}, \mathrm{MgCl}^{+}$ intercalation capacity increases significantly (Fig. 5e). This improvement can be attributed to increased $\mathrm{MgCl}^{+}$diffusivity; considering the migration barrier of $0.18 \mathrm{eV}$ for $\mathrm{MgCl}^{+}$in exTiS 2 , the diffusivity increases to $209 \%$ when temperature increases from 25 to $60^{\circ} \mathrm{C}$ according to Arrhenius relation with temperature $\left(D \propto \mathrm{e}^{-E_{\mathrm{a}} / k T}\right)$. At $60^{\circ} \mathrm{C}$, the cell reaches a capacity of $400 \mathrm{mAh} \mathrm{g}_{\mathrm{TiS}_{2}}{ }^{-1}\left(394 \mathrm{Ah} \mathrm{L}^{-1}\right)$, or $269 \mathrm{mAh} \mathrm{g}^{-1}$ based on the 
Pristine $\mathrm{TiS}_{2}$

Initial expansion

by PY $14^{+}$intercalation

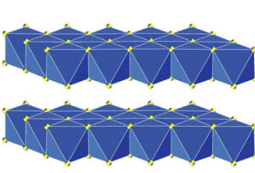

Stage 0

$c=5.69 \AA$

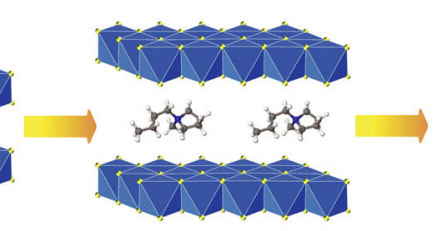

Stage 1

$c=10.86 \AA$
Further expansion by $\mathrm{MgCl}^{+}$and $\mathrm{PY} 14^{+}$

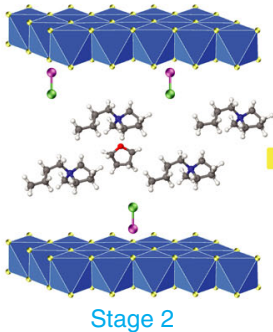

$c=18.63 \AA$
Structural distortion

by $\mathrm{MgCl}^{+}$intercalation

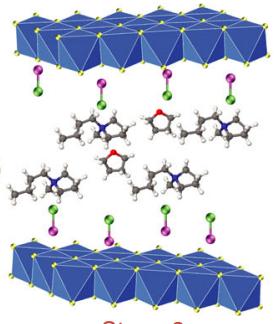

Stage 3

$c=18.63 \AA$

\section{$\therefore \mathrm{TiS}_{2}$ \\ -0 $\mathrm{MgCl}^{+}$ \\ 1. \\ 2 THF}

Fig. $6 \mathrm{~A}$ schematic of structural evolution of $\mathrm{TiS}_{2}$ at different stages of intercalation. Interlayers are expanded or distorted as different amount of pillaring molecules, complex cations, and solvents are intercalated into the van der Waals gap of a host material at each stage

mass of the composite, corresponding to the intercalation of 1.7 $\mathrm{MgCl}^{+}$per unit $\mathrm{TiS}_{2}$. Discharging at a lower rate $\left(24 \mathrm{~mA} \mathrm{~g}^{-1}\right)$ at $60{ }^{\circ} \mathrm{C}$ yielded the capacity of $450 \mathrm{mAh} \mathrm{g}^{-1}\left(1.9 \mathrm{MgCl}^{+}\right.$per $\left.\mathrm{TiS}_{2}\right)$, which was in accordance with $\mathrm{Mg} / \mathrm{Ti}$ ratio of $2.1 \pm 0.3$ from the EDS spectrum (Fig. 5f). Having more than one electron reversibly stored per $\mathrm{TiS}_{2}$ formula is to our knowledge unprecedented. Each $1 \mathrm{~T}-\mathrm{TiS}_{2}$ unit possesses two distinguishable sites: the octahedral (Ti top) and tetrahedral (hollow top) sites. Without interlayer expansion, only one site is energetically viable for ion intercalation (octahedral site in this case). Intercalation of a monovalent ion in a tetrahedral site only happens at an exceedingly low potential $^{60}\left(-0.27 \mathrm{~V}\right.$ vs $\left.\mathrm{Mg} / \mathrm{Mg}^{2+}\right)$ and the process is not reversible (Supplementary Fig. 12). When $\mathrm{TiS}_{2}$ is expanded, intercalation at both sites will exhibit similar energy levels per our simulation results (Fig. 2b), thereby enabling the intercalation of more than one $\mathrm{MgCl}^{+}$per unit $\mathrm{TiS}_{2}$. In summary, the $\mathrm{MgCl}^{+}$ intercalation into exTiS 2 is fully reversible over a wide temperature range from -45 to $60^{\circ} \mathrm{C}$. Higher temperature leads to higher $\mathrm{MgCl}^{+}$diffusivity and nearly doubled reversible capacity.

\section{Discussion}

A schematic illustration in Fig. 6 summarizes the four stages of intercalation. From stage 0 to 1 , the interlayer distance increases from $5.69 \AA$ to $10.86 \AA$ due to the intercalation of $\mathrm{PY} 14^{+}$ions, which act as pillars to expand $\mathrm{TiS}_{2}$ and make it possible for $\mathrm{MgCl}^{+}$ions to intercalate inside the gap. From stage 1 to 2 , the interlayer distance further increases to $18.63 \AA$ as $\mathrm{MgCl}^{+}$ions begin to intercalate thanks to the initial expansion by $\mathrm{PY} 14^{+}$ions. A small number of THF molecules are intercalated during this step. From stage 2 to 3, a large number of $\mathrm{MgCl}^{+}$ions are intercalated and the corresponding mechanical stress results in structural distortions (Fig. 3b). Following these steps, PY14 ${ }^{+}$ions stay inside the van der Waals gap, whereas the highly mobile $\mathrm{MgCl}^{+}$is (de)intercalated reversibly. After the completion of the first discharge process, the interlayer-expanded $\mathrm{TiS}_{2}$ cathode shows a reversible capacity as high as $239 \mathrm{mAhg}^{-1}$ (Fig. 5a). Completing stage 3 was essential in realizing such a large reversible capacity; stopping at stage 2 led to a lower reversible capacity of ca. $60 \mathrm{mAh} \mathrm{g}^{-1}$ even though $\mathrm{TiS}_{2}$ is expanded to the same interlayer distance for stages 2 and 3 (Supplementary Fig. 13). It is noteworthy that the theoretical predictions suggest no difference in the diffusivity of $\mathrm{MgCl}^{+}$as long as the interlayer distance is larger than $10.9 \AA$. However, the theoretical modeling does not account for the steric hindrance of the intercalated PY $14^{+}$cations. Therefore, in reality, fast diffusion of $\mathrm{MgCl}^{+}$may require more substantial structural adjustments (e.g., interlayer expansion to 18.6 $\AA$, intralayer ruptures as shown in Fig. 3 b, etc.), which make the structure more accessible to $\mathrm{MgCl}^{+}$ions. Further engineering of less bulky and more light-weight pillar species may require smaller structural adjustments and also lead to higher specific capacity (which is determined by the total mass of the host and the pillar).

The following electrochemical reactions are proposed for room temperature:

$$
\begin{aligned}
& \text { Cathode: } \operatorname{exTiS}_{2}+\mathrm{MgCl}^{+}+e^{-} \leftrightarrow(\mathrm{MgCl}) \mathrm{exTiS}_{2}, \\
& \begin{array}{r}
\text { Anode: } n \mathrm{Mg}+\mathrm{Mg}_{x} \mathrm{Cl}_{y}^{z+} \leftrightarrow y \mathrm{MgCl}^{+}+2 n e^{-}, \\
\text {Overall: } 2 \mathrm{exTiS}_{2}+\mathrm{Mg}+1 / n \mathrm{Mg}_{x} \mathrm{Cl}_{y}^{z+} \leftrightarrow z / n \mathrm{MgCl}^{+} \\
+2(\mathrm{MgCl}) \mathrm{exTiS}_{2}
\end{array}
\end{aligned}
$$

where $\mathrm{Mg}_{x} \mathrm{Cl}_{y}{ }^{z+}$ refers to $\mathrm{MgCl}_{2}, \mathrm{Mg}_{2} \mathrm{Cl}_{3}{ }^{+}, \mathrm{Mg}_{3} \mathrm{Cl}_{5}{ }^{+}$, etc. so that $x$, $y, z$, and $n$ are whole numbers that satisfy $y>x, z=2 x-y=0$ or 1 , and $n=y-x=1,2,3$, etc. Equation (1) describes the reversible intercalation of $\mathrm{MgCl}^{+}$into exTiS 2 at the cathode side. This complex-ion intercalation mechanism is similar to the $\mathrm{AlCl}_{4}{ }^{-}$ intercalation in graphite reported by Dai et al. ${ }^{61}$, except that the intercalation of $\mathrm{MgCl}^{+}$happens during the reduction of the host rather than the oxidation. Equation (2) describes the simultaneous generation of $\mathrm{MgCl}^{+}$at the $\mathrm{Mg}$ anode by converting $\mathrm{Mg}_{x} \mathrm{Cl}_{y}{ }^{z+}$ species in the electrolyte. The overall battery reaction in Eq. (3) can continue as long as $\mathrm{Mg}_{x} \mathrm{Cl}_{y}{ }^{z+}$ species are available in the electrolyte. Equation (3) depicts that $\mathrm{MgCl}_{2}$ is converted to intercalated $\mathrm{MgCl}^{+}$without leaving anything behind because it is neutral $(z=0)$, whereas complex cations with $y>x$ are converted leaving $\mathrm{MgCl}^{+}$of same $z / n$ equivalents in the electrolyte. Therefore, the cation concentration of the electrolyte stays unchanged throughout the reaction in either case.

According to Eq. (3), two moles of $(\mathrm{MgCl}) \mathrm{TiS}_{2}$ are formed with the consumption of one mole of magnesium-chloride $\left(\mathrm{MgCl}_{2}\right)$. Considering a $1 \mathrm{M}$ concentration for $\mathrm{MgCl}_{2}{ }^{62}$, the necessary volume of electrolyte to match an areal capacity of $1 \mathrm{mAh} \mathrm{cm}$ (which approximates the areal capacity of a practical cell) is 18.7 $\mu \mathrm{L} \mathrm{cm}{ }^{-2}$. This amount of electrolyte is sufficiently small to be accommodated in practical batteries; commercial separators with $300 \mu \mathrm{m}$ thickness and $80 \%$ porosity may uptake $24 \mu \mathrm{L} \mathrm{cm}^{-2}$ of electrolyte ${ }^{63}$. Further scale-up of the battery cell can be supported by adding $\mathrm{MgCl}_{2}$, which is the main neutral species in the chloride-based electrolytes ${ }^{20,64,65}$. Dissolved $\mathrm{MgCl}_{2}$ can participate in the battery reaction of Eq. (2) directly, or indirectly by buffering $\mathrm{Mg}_{2} \mathrm{Cl}_{3}{ }^{+}$through the dynamic equilibrium among $\mathrm{MgCl}_{2}, \mathrm{MgCl}^{+}$, and $\mathrm{Mg}_{2} \mathrm{Cl}_{3}{ }^{+}$species ${ }^{36}$. Recent reports show the solubility of $\mathrm{MgCl}_{2}$ can be greatly increased with the aid of diorganomagnesium compounds ${ }^{62}$.

The $\mathrm{MgCl}$-ion storage mechanism can be generalized to other two-dimensional materials. For example, molybdenum disulfide $\left(\mathrm{MoS}_{2}\right)$ also demonstrated ca. $280 \mathrm{mAh} \mathrm{g}^{-1}$ after 10 cycles in the 
APC electrolyte containing PY14 $4^{+}$ions (Supplementary Fig. 14). The average discharge voltage of $0.7 \mathrm{~V}$ in this work needs to be increased in future studies by exploring higher voltage cathodes. Attempts to use the same approach for high-voltage cathode (e.g., layered vanadium oxide) was not quite successful so far due to the limitation of the nucleophilic nature of the APC electrolyte, which reacts chemically with oxides. It is worthwhile to re-examine this method to layered oxide cathodes, when non-nucleophilic electrolytes with higher voltage stability window become widely available ${ }^{24}$.

Recent years have seen increasing concerns about potential corrosion problems related to chloride-containing electrolytes. $\mathrm{Oh}$ and colleagues ${ }^{66}$ have reported that $\mathrm{PY} 14 \mathrm{Cl}$ is an effective inhibitor against the corrosion by $\mathrm{Cl}^{-}$at high potentials. Therefore, PY $14^{+}$is not only a pillar for expanding $\mathrm{TiS}_{2}$ but also a corrosion inhibitive additive. Meanwhile, halogen-free electrolytes are under development for even wider voltage windows ${ }^{24}$. In those cases, the anion $\left(\mathrm{A}^{-}\right)$can associate with $\mathrm{Mg}^{2+}$ to form $\mathrm{MgA}^{+}$ions, which can be used as the charge carrier in expanded materials. In this sense, the present study provides general guidelines and design principles for the intercalation of such generalized $\mathrm{Mg}$ complex ions into expanded interlayers.

In summary, we report a magnesium battery chemistry enabled by $\mathrm{MgCl}^{+}$intercalation mechanism. A class of two-dimensional host materials with electrochemically expanded interlayer spacing allow intercalation of the large $\mathrm{MgCl}^{+}$. With the expanded cathode, the reversible capacity and rate performance of an exTiS $/ \mathrm{Mg}$ full cell surpass those of state-of-the-art MRBs. This work unravels the factors that determine the diffusion of ions in layered materials with respect to the interlayer distance and chemical interactions. And a new direction is identified toward overcoming the challenge of high-migration energy barrier and kinetically sluggish dissociation processes in MRBs. This battery chemistry can be extended to the intercalation of a wide range of multivalent ions (e.g., $\mathrm{Zn}^{2+}, \mathrm{Ca}^{2+}, \mathrm{Al}^{3+}$ ) into various twodimensional materials, highlighting the importance of an unexploited route of materials design for multivalent-ion batteries.

\section{Methods}

First-principles calculations. Minimum energy pathway and the corresponding migration energy barrier were calculated using the climbing image nudged elastic band method ${ }^{67}$. The total energy calculations of each image along the pathway were performed in a supercell geometry described below using first-principles density functional theory as implemented in the Vienna Ab-initio Simulation Package (VASP) ${ }^{68}$. More specifically, we adopted the projector-augmented wave method $^{69}$, a plane wave basis with kinetic energy cut-off of $400 \mathrm{eV}$, a $\Gamma$-centered Monkhorst-Pack $k$-point sampling of $3 \times 3 \times 1$ for Brillouin zone integration ${ }^{70}$ in the supercell calculations, and the exchange-correlation functional in the Perdew-Berke-Ernzerhof $(\mathrm{PBE})^{71}$ form within the generalized gradient approximation $(\mathrm{GGA})^{72}$. In addition, van der Waals interaction was approximated by including the optB88-vdW nonlocal correlation functional ${ }^{73}$. The calculated $a$ and $c$ lattice parameter of bulk $1 \mathrm{~T}-\mathrm{TiS}_{2}$ are $3.414 \AA$ and $5.273 \AA$. A double layer supercell consisting of $4 \times 4 \times 2 \mathrm{TiS}_{2}$ unit cells with one $\mathrm{Mg}^{2+}$ was constructed to determine the migration barrier in the dilute limit with varied $c$ lattice constant of 5.7-6.3 $\AA$. For larger $c$ lattice constant of 9.8-18.6 $\AA$, a single layer supercell of $4 \times$ $4 \times 1 \mathrm{TiS}_{2}$ unit cells with one $\mathrm{Mg}^{2+}$ or $\mathrm{MgCl}^{+}$was constructed. At such large $c$ lattice constant, calculation with either single or double layer supercell resulted in almost same migration barrier. The charge difference plots were calculated by subtracting the valence electron density of isolated neutral $\mathrm{Mg}$ and $\mathrm{Cl}$ atoms and pristine $\mathrm{TiS}_{2}$ layers from that of $\mathrm{Mg} @ \mathrm{TiS}_{2}$ and $\mathrm{MgCl} @ \mathrm{TiS}_{2}$ using an isosurface value of $0.015 e \AA^{-3}$

Materials preparation. Layered $\mathrm{TiS}_{2}$ (99.8\%, Strem Chemical Inc.) with an average particle size of $10 \mu \mathrm{m}$ was used as purchased. A slurry of active material (70 wt.\%), Super-P carbon (20 wt.\%), and polyvinylidene fluoride (10 wt.\%) dispersed in $\mathrm{N}$-methyl-2-pyrrolidone was spread on a piece of stainless steel mesh (400 mesh, $0.8 \mathrm{~cm}^{2}$ ) and dried as the working electrode with active material mass loading of $0.5-1 \mathrm{mg} \mathrm{cm}^{-2}$. To prepare samples for analysis, we prepared electrode by cold pressing $7 \mathrm{mg}$ of $\mathrm{TiS}_{2}$ powders onto stainless steel mesh at $10 \mathrm{MPa}$ without using binder or conductive agent. Freshly polished magnesium foil $(50 \mu \mathrm{m}$ thick, $99.95 \%$,
GalliumSource, LLC) was used as both the counter and reference electrodes in 2- or 3-electrode cell tests. Standard APC electrolyte, a solution of $0.25 \mathrm{M}$ $\left[\mathrm{Mg}_{2} \mathrm{Cl}_{3}\right]^{+}\left[\mathrm{AlPh}_{2} \mathrm{Cl}_{2}\right]^{-}$in THF, was prepared following Aurbach et al. and was used as the Mg-ion electrolyte throughout this work ${ }^{19}$. PY14 ${ }^{+}$ion was added in the APC electrolyte by dissolving 1-butyl-1-methylpyrrolidinium chloride ( $\mathrm{PY} 14 \mathrm{Cl},>98 \%$, TCI America Co.) to the concentration of $0.2 \mathrm{M}$.

Electrochemical tests. 2- and 3-electrode coin cells were fabricated in an Ar-filled glove box using a magnesium foil as the anode, a glass fiber separator $(210 \mu \mathrm{m}$ thick, grade 691, VWR Co.) and a tri-layer polypropylene/polyethylene/polypropylene ( $25 \mu \mathrm{m}$ thick, Celgard 2325, Celgard LLC.) as the separators, and $\mathrm{TiS}_{2}$ or $\mathrm{exTiS}_{2}$ as the cathode. The electrochemical measurements for CV, EIS, and GITT were carried out in a specially designed 3-electrode coin cell (Supplementary Fig. 15) to measure the potential of cathode vs $\mathrm{Mg} / \mathrm{Mg}^{2+}$. For the 3-electrode configuration, a ring-shaped magnesium foil was used as the reference electrode connected out of the coin cell by polypropylene coated stainless steel foil. The electrochemical characterizations were conducted using a potentiostat (VMP-3, Bio-Logic Co.) and battery cyclers (CT2001A, Lanhe Co.) at room temperature. EIS was measured at a fixed potential of $1.8 \mathrm{~V}$ vs $\mathrm{Mg} / \mathrm{Mg}^{2+}$ by applying small sinusoidal potential with amplitude of $7 \mathrm{mV}$ and frequency $(f)$ ranging from $200 \mathrm{kHz}$ to 2 $\mathrm{mHz}$. Capacitance was obtained as a function of frequency by calculating the real part of the complex capacitance ${ }^{74}$. Before the electrochemical cycling, all the cells were activated at $25^{\circ} \mathrm{C}$ by discharging the $\mathrm{TiS}_{2} / \mathrm{Mg}$ cells to $0 \mathrm{~V}$ vs $\mathrm{Mg} / \mathrm{Mg}^{2+}$ at 5 $\mathrm{mA} \mathrm{g}^{-1}$ for ca. $100 \mathrm{~h}$ and subsequent cycling the cells within $0-2 \mathrm{~V}$ vs $\mathrm{Mg} / \mathrm{Mg}^{2+}$ at $24 \mathrm{~mA} \mathrm{~g}^{-1}$ for 10 cycles (as shown in Fig. 3a). Then the activated exTiS $2 / \mathrm{Mg}$ cells were cycled within $0-2 \mathrm{~V}$ vs $\mathrm{Mg} / \mathrm{Mg}^{2+}$ at varied temperature from -45 to $60^{\circ} \mathrm{C}$. The capacity was calculated based on the mass of $\mathrm{TiS}_{2}$ in the electrode unless otherwise specified; the specific capacity of $400 \mathrm{mAh} \mathrm{g}^{-1}$ translated to $1.7 \mathrm{MgCl}^{+}$ per $\mathrm{TiS}_{2}$ by comparing with the theoretical value of $239.3 \mathrm{mAh} \mathrm{g}^{-1}$ for the intercalation of $1 \mathrm{MgCl}^{+}$into $\mathrm{TiS}_{2}$. GITT was performed by applying constant current of $24 \mathrm{~mA} \mathrm{~g}^{-1}$ for $20 \mathrm{~min}$ followed by $30 \mathrm{~min}$ of open circuit period upon charging and discharging.

Materials characterization. The electrodes were characterized by scanning electron microscopy (SEM, LEO Gemini 1525, ZWL Co.), EDS (Oxford Instruments Co.), XPS (Physical Electronics Model 5700), ICP-OES (Agilent Technologies, Model 725), NMR (Oxford Instruments EUR0059), and STEM (Nion Co. Model UltraSTEM 100). STEM imaging was performed at $60 \mathrm{kV}$ to reduce the electron knock-on damage. The convergence angle is set to be $\sim 30 \mathrm{mrad}$. All STEM images were acquired from $\sim 86-200$ mrad range. In operando XRD was measured using SmartLab ${ }^{\circledR}$ X-ray diffraction system (Rigaku Co.) with a battery cell attachment. XRD patterns were scanned by D/teX Ultra 250 detector from $2 \theta=3^{\circ}$ to $40^{\circ}$ with step size of $0.04^{\circ}$ and scanning speed of $1^{\circ}$ or $2^{\circ}$ per minute under Bragg-Brentano focusing. $\mathrm{Cu} K_{\alpha}$ radiation $(\lambda=1.5405 \AA)$ was used and the voltage and current was $40 \mathrm{kV}$ and $44 \mathrm{~mA}$, respectively. Ring-shaped $\mathrm{Mg}$ metal anode was placed on the $\mathrm{Be}$ window to avoid electrochemical dissolution of Be metal at $>0.53 \mathrm{~V}$ vs $\mathrm{Mg} / \mathrm{Mg}^{2+}$ HE-XRD was carried out at beamline 11-ID-C of the Advanced Photon Source (APS) at Argonne National Laboratory (ANL). The wavelength of the X-ray was $0.10798 \AA$ A; such high-energy X-ray has a large penetration depth that allowed for the detection of structural changes of the bulk material. The $\mathrm{TiS}_{2}$ powder was collected, put into kapton tube, and sealed by epoxy glue inside the glove box. A Perkin Elmer large area X-ray detector was used to collect the 2-dimensional diffraction patterns in transmission mode. The measured 2-dimensional diffraction patterns were calibrated using a standard $\mathrm{CeO}_{2}$ sample and converted to 1dimensional intensity vs the diffraction angle $(2 \theta)$ patterns using Fit2D software ${ }^{75}$ The diffraction peaks were assigned to lattice planes $(h k l)$ by simulating the patterns of $\mathrm{TiS}_{2}$ with the corresponding interlayer distance using PowderCell 2.4 software $^{76}$. Mg K-edge NEXAFS experiment was performed on beamline 6.3.1.2 (ISAAC) at the Advanced Light Source, Lawrence Berkeley National Laboratory with both total electron yield (TEY) and total fluorescence yield (TFY) detection modes simultaneously. XAS spectra were energy calibrated by measuring $\mathrm{MgO}$ before and after the measurements. The NEXAFS measurements at $\mathrm{S} K$-edge were performed at the Advanced Photon Source (APS) on the bending-magnet beamline 9-BM-B with electron energy of $7 \mathrm{GeV}$ and average current of $100 \mathrm{~mA}$. The radiation was monochromatized by a $\mathrm{Si}(111)$ double-crystal monochromator Harmonic rejection was accomplished with Harmonic rejection mirror. All spectra of samples were collected in fluorescence mode by Vortex detector. For energy calibration, the peak position of sodium thiosulfate was adjusted to $2469.2 \mathrm{eV}$ by Gaussian fitting. Data reduction and analysis were processed by Athena software. ${ }^{1} \mathrm{H}-\mathrm{NMR}$ samples were prepared by suspending thoroughly washed and dried samples in DMSO- $d_{6}$ by ultrasonication for $0.5 \mathrm{~h}$ and then heated at $70{ }^{\circ} \mathrm{C}$ for $1 \mathrm{~h}$ in a tight-sealed vial. ${ }^{1} \mathrm{H}-\mathrm{NMR}\left(400 \mathrm{MHz}, \mathrm{DMSO}-d_{6}, \delta\right)$ of PY14${ }^{+}: 0.918(t, 3 \mathrm{H})$, $1.298(\mathrm{~m}, 2 \mathrm{H}), 1.660(\mathrm{~m}, 2 \mathrm{H}), 2.060(\mathrm{~m}, 4 \mathrm{H}), 2.955(\mathrm{~s}, 3 \mathrm{H})$; of THF: 1.747 (quint, $4 \mathrm{H}), 3.589(t, 4 \mathrm{H})$. The composition for stage 3 was determined by combining thermogravimetric analysis (TGA), ${ }^{1} \mathrm{H}-\mathrm{NMR}$, and ICP results. The gross value of weight percentage of PY14 and THF was obtained by TGA, because both of the organic species evaporate or completely decompose to gaseous products by $500{ }^{\circ} \mathrm{C}$ in an inert atmosphere ${ }^{77}$. Then the molar ratio of PY14 and THF $(x / y)$ was measured by ${ }^{1} \mathrm{H}-\mathrm{NMR}$ and the molar ratio of $\mathrm{Mg}$ to $\mathrm{Ti}(z)$ was measured by ICPOES 
Data availability. The data that support the findings of this study are available from the corresponding author upon request.

Received: 20 January 2017 Accepted: 26 June 2017

Published online: 24 August 2017

\section{References}

1. Aurbach, D. et al. Prototype systems for rechargeable magnesium batteries. Nature 407, 724-727 (2000).

2. Ling, C., Banerjee, D. \& Matsui, M. Study of the electrochemical deposition of $\mathrm{Mg}$ in the atomic level: why it prefers the non-dendritic morphology. Electrochim. Acta 76, 270-274 (2012).

3. Liu, M. et al. Spinel compounds as multivalent battery cathodes: a systematic evaluation based on ab initio calculations. Energy Environ. Sci. 8, 964-974 (2015).

4. Muldoon, J., Bucur, C. B. \& Gregory, T. Quest for nonaqueous multivalent secondary batteries: magnesium and beyond. Chem. Rev. 114, 11683-11720 (2014).

5. Aurbach, D. et al. Progress in rechargeable magnesium battery technology. Adv. Mater. 19, 4260-4267 (2007).

6. Wang, R. Y., Wessells, C. D., Huggins, R. A. \& Cui, Y. Highly reversible open framework nanoscale electrodes for divalent Ion batteries. Nano Lett. 13, 5748-5752 (2013).

7. Lukatskaya, M. R. et al. Cation intercalation and high volumetric capacitance of two-dimensional titanium carbide. Science 341, 1502-1505 (2013).

8. Saha, P. et al. Rechargeable magnesium battery: current status and key challenges for the future. Prog. Mater. Sci. 66, 1-86 (2014).

9. Bucur, C. B., Gregory, T., Oliver, A. G. \& Muldoon, J. Confession of a magnesium battery. J. Phys. Chem. Lett. 6, 3578-3591 (2015).

10. Kim, C. et al. Direct observation of reversible magnesium ion intercalation into a spinel oxide host. Adv. Mater. 27, 3377-3384 (2015)

11. Gu, Y., Katsura, Y., Yoshino, T., Takagi, H. \& Taniguchi, K. Rechargeable magnesium-ion battery based on a TiSe ${ }_{2}$-cathode with $d$ - $p$ orbital hybridized electronic structure. Sci. Rep. 5, 12486 (2015).

12. Arthur, T. S. et al. Amorphous $\mathrm{V}_{2} \mathrm{O}_{5}-\mathrm{P}_{2} \mathrm{O}_{5}$ as high-voltage cathodes for magnesium batteries. Chem. Commun. 51, 15657-15660 (2015).

13. Zhang, R., Arthur, T. S., Ling, C. \& Mizuno, F. Manganese dioxides as rechargeable magnesium battery cathode; synthetic approach to understand magnesiation process. J. Power Sources 282, 630-638 (2015).

14. Zhang, R., Mizuno, F. \& Ling, C. Fullerenes: non-transition metal clusters as rechargeable magnesium battery cathodes. Chem. Commun. 51, 1108-1111 (2015)

15. Tepavcevic, S. et al. Nanostructured layered cathode for rechargeable Mg-ion batteries. ACS Nano 9, 8194-8205 (2015).

16. Sun, X. et al. A high capacity thiospinel cathode for Mg batteries. Energy Environ. Sci. 9, 2273-2277 (2016).

17. Sun, X., Bonnick, P. \& Nazar, L. F. Layered $\mathrm{TiS}_{2}$ positive electrode for $\mathrm{Mg}$ batteries. ACS Energy Lett. 1, 297-301 (2016).

18. Chusid, O. et al. Solid-state rechargeable magnesium batteries. Adv. Mater. 15, 627-630 (2003)

19. Mizrahi, O. et al. Electrolyte solutions with a wide electrochemical window for rechargeable magnesium batteries. J. Electrochem. Soc. 155, A103-A109 (2008).

20. Pour, N., Gofer, Y., Major, D. T. \& Aurbach, D. Structural analysis of electrolyte solutions for rechargeable $\mathrm{mg}$ batteries by stereoscopic means and DFT calculations. J. Am. Chem. Soc. 133, 6270-6278 (2011)

21. Kim, H. S. et al. Structure and compatibility of a magnesium electrolyte with a sulphur cathode. Nat. Commun. 2, 427 (2011)

22. Yamanaka, T., Hayashi, A., Yamauchi, A. \& Tatsuinisago, M. Preparation of magnesium ion conducting $\mathrm{MgS}-\mathrm{P}_{2} \mathrm{~S}_{5}-\mathrm{MgI}_{2}$ glasses by a mechanochemical technique. Solid State Ionics 262, 601-603 (2014).

23. Mohtadi, R. \& Mizuno, F. Magnesium batteries: current state of the art, issues and future perspectives. Beilstein J. Nanotechnol. 5, 1291-1311 (2014).

24. Tutusaus, O. et al. An efficient halogen-free electrolyte for use in rechargeable magnesium batteries. Angew. Chem. Int. Ed. 54, 7900-7904 (2015).

25. Cheng, Y. W. et al. Highly active electrolytes for rechargeable Mg batteries based on a $\left[\mathrm{Mg}_{2}(\mathrm{~m}-\mathrm{Cl})_{2}\right]^{2+}$ cation complex in dimethoxyethane. Phys. Chem. Chem. Phys. 17, 13307-13314 (2015).

26. Arthur, T. S., Singh, N. \& Matsui, M. Electrodeposited Bi, Sb and Bi1-xSbx alloys as anodes for Mg-ion batteries. Electrochem. Commun. 16, 103-106 (2012).

27. Shao, Y. et al. Highly reversible $\mathrm{Mg}$ insertion in nanostructured $\mathrm{Bi}$ for $\mathrm{Mg}$ ion batteries. Nano Lett. 14, 255-260 (2014)

28. $\mathrm{Wu}, \mathrm{N}$. et al. A highly reversible, low-strain Mg-ion insertion anode material for rechargeable Mg-ion batteries. NPG Asia Mater. 6, el20 (2014).

29. Cheng, Y. et al. Interface promoted reversible $\mathrm{Mg}$ insertion in nanostructured Tin-Antimony Alloys. Adv. Mater. 27, 6598-6605 (2015).
30. Yoo, H. D. et al. Mg rechargeable batteries: an on-going challenge. Energy Environ. Sci. 6, 2265-2279 (2013).

31. Huie, M. M., Bock, D. C., Takeuchi, E. S., Marschilok, A. C. \& Takeuchi, K. J. Cathode materials for magnesium and magnesium-ion based batteries. Coord. Chem. Rev. 287, 15-27 (2015).

32. Viestfrid, Y., Levi, M. D., Gofer, Y. \& Aurbach, D. Microelectrode studies of reversible $\mathrm{Mg}$ deposition in THF solutions containing complexes of alkylaluminum chlorides and dialkylmagnesium. J. Electroanal. Chem. 576, 183-195 (2005).

33. Wan, L. W. F. \& Prendergast, D. The solvation structure of Mg Ions in dichloro complex solutions from first-principles molecular dynamics and simulated X-ray absorption spectra. J. Am. Chem. Soc. 136, 14456-14464 (2014).

34. Mizuno, F. et al. Understanding and overcoming the challenges posed by electrode/electrolyte interfaces in rechargeable magnesium batteries. Front. Energy Res. 2, 46 (2014).

35. Canepa, P. et al. Understanding the initial stages of reversible Mg deposition and stripping in inorganic non-aqueous electrolytes. Chem. Mater. 27, 3317-3325 (2015).

36. Liu, T. et al. A fundamental study on the $\left[(\mathrm{m}-\mathrm{Cl})_{3} \mathrm{Mg}_{2}(\mathrm{THF})_{6}\right]^{+}$dimer electrolytes for rechargeable $\mathrm{Mg}$ batteries. Chem. Commun. 51, 2312-2315 (2015).

37. Wan, L. F., Perdue, B. R., Apblett, C. A. \& Prendergast, D. Mg desolvation and intercalation mechanism at the $\mathrm{Mo}_{6} \mathrm{~S}_{8}$ chevrel phase surface. Chem. Mater. 27, 5932-5940 (2015).

38. Canepa, P. et al. Elucidating the structure of the magnesium aluminum chloride complex electrolyte for magnesium-ion batteries. Energy Environ. Sci. 8, 3718-3730 (2015).

39. Brouillet, E. V. et al. Exposing elusive cationic magnesium-chloro aggregates in aluminate complexes through donor control. Dalton Trans. 45, 5590-5597 (2016).

40. Levi, E., Levi, M. D., Chasid, O. \& Aurbach, D. A review on the problems of the solid state ions diffusion in cathodes for rechargeable $\mathrm{Mg}$ batteries. $J$. Electroceram. 22, 13-19 (2009).

41. Emly, A. \& Van der Ven, A. Mg intercalation in layered and spinel host crystal structures for Mg batteries. Inorg. Chem. 54, 4394-4402 (2015).

42. Goward, G. R., Leroux, F. \& Nazar, L. F. Poly(pyrrole) and poly(thiophene)/ vanadium oxide interleaved nanocomposites: positive electrodes for lithium batteries. Electrochim. Acta 43, 1307-1313 (1998).

43. Kerr, T. A., Wu, H. \& Nazar, L. F. Concurrent polymerization and insertion of aniline in molybdenum trioxide: formation and properties of a [poly (aniline) $]_{0.24} \mathrm{MoO}_{3}$ nanocomposite. Chem. Mater. 8, 2005-2015 (1996).

44. Lemmon, J. P. \& Lerner, M. M. Preparation and characterization of nanocomposites of polyethers and molybdenum disulfide. Chem. Mater. 6, 207-210 (1994).

45. Powell, A. V. Chapter 7. Intercalation compounds of low-dimensional transition metal chalcogenides. Annu. Rep. Prog. Chem. Sect. C Phys. Chem. 90, 177-213 (1993)

46. Wan, C. et al. Flexible n-type thermoelectric materials by organic intercalation of layered transition metal dichalcogenide $\mathrm{TiS}_{2}$. Nat. Mater. 14, 622-627 (2015).

47. Jeong, S. et al. Tandem intercalation strategy for single-layer nanosheets as an effective alternative to conventional exfoliation processes. Nat. Commun. 6 , 5763 (2015).

48. Letaief, S. \& Detellier, C. Ionic liquids-kaolinite nanostructured materials. intercalation of pyrrolidinium salts. Clays Clay Miner. 56, 82-89 (2008).

49. Appetecchi, G. B., Montanino, M. \& Passerini, S. in Ionic Liquids: Science and Applications (eds Visser, A. E., Bridges, N. J. \& Rogers, R. D.) (American Chemical Society, 2012).

50. Nakayama, Y. et al. Complex structures and electrochemical properties of magnesium electrolytes. J. Electrochem. Soc. 155, A754-A759 (2008).

51. Benmayza, A. et al. Effect of electrolytic properties of a magnesium Organohaloaluminate electrolyte on magnesium deposition. J. Phys. Chem. C 117, 26881-26888 (2013).

52. Wu, Z. Y. et al. Sulfur $K$-edge X-ray-absorption study of the charge transfer upon lithium intercalation into titanium disulfide. Phys. Rev. Lett. 77, 2101-2104 (1996).

53. Cheng, Y. et al. Facile synthesis of chevrel phase nanocubes and their applications for multivalent energy storage. Chem. Mater. 26, 4904-4907 (2014).

54. Jing, S. et al. Density functional theory study of $\mathrm{Li}, \mathrm{Na}$, and $\mathrm{Mg}$ intercalation and diffusion in $\mathrm{MoS}_{2}$ with controlled interlayer spacing. Mater. Res. Express 3 , 064001 (2016).

55. Weppner, W. \& Huggins, R. A. Determination of the kinetic parameters of mixed-conducting electrodes and application to the system $\mathrm{Li}_{3} \mathrm{Sb}$. $J$. Electrochem. Soc. 124, 1569-1578 (1977)

56. Yu, H. C. et al. Designing the next generation high capacity battery electrodes. Energy Environ. Sci. 7, 1760-1768 (2014)

57. Van der Ven, A., Bhattacharya, J. \& Belak, A. A. Understanding Li diffusion in Li-intercalation compounds. Acc. Chem. Res. 46, 1216-1225 (2013). 
58. Liang, Y. et al. Interlayer-expanded molybdenum disulfide nanocomposites for electrochemical magnesium storage. Nano Lett. 15, 2194-2202 (2015).

59. Levi, M. D. et al. Phase transitions and diffusion kinetics during $\mathrm{Mg}^{2+}$ - and $\mathrm{Li}^{+}$-ion insertions into the $\mathrm{Mo}_{6} \mathrm{~S}_{8}$ chevrel phase compound studied by PITT. Electrochim. Acta 49, 3201-3209 (2004).

60. Suslov, E. A., Bushkova, O. V., Sherstobitova, E. A., Reznitskikh, O. G. \& Titov, A. N. Lithium intercalation into $\mathrm{TiS}_{2}$ cathode material: phase equilibria in a $\mathrm{Li}_{-}-\mathrm{TiS}_{2}$ system. Ionics 22, 503-514 (2016).

61. Lin, M.-C. et al. An ultrafast rechargeable aluminium-ion battery. Nature 520, 324-328 (2015)

62. Liao, C. et al. The unexpected discovery of the $\mathrm{Mg}(\mathrm{HMDS})_{2} / \mathrm{MgCl}_{2}$ complex as a magnesium electrolyte for rechargeable magnesium batteries. J. Mater. Chem. A 3, 6082-6087 (2015).

63. Cook, J. \& Kritzer, P. in Encyclopedia of Electrochemical Power Sources (ed. Garche, J.) (Elsevier, 2009).

64. Gregory, T. D., Hoffman, R. J. \& Winterton, R. C. Nonaqueous electrochemistry of magnesium: applications to energy storage. J. Electrochem. Soc. 137, 775-780 (1990).

65. Vestfried, Y., Chusid, O., Goffer, Y., Aped, P. \& Aurbach, D. Structural analysis of electrolyte solutions comprising magnesium-aluminate chloro-organic complexes by raman spectroscopy. Organometallics 26, 3130-3137 (2007).

66. Ha, J. H., Cho, J.-H., Kim, J. H., Cho, B. W. \& Oh, S. H. 1-Butyl-1methylpyrrolidinium chloride as an effective corrosion inhibitor for stainless steel current collectors in magnesium chloride complex electrolytes. J. Power Sources 355, 90-97 (2017).

67. Henkelman, G., Uberuaga, B. P. \& Jónsson, H. A climbing image nudged elastic band method for finding saddle points and minimum energy paths. J. Chem. Phys. 113, 9901-9904 (2000).

68. Kresse, G. \& Furthmüller, J. Efficient iterative schemes for ab initio total-energy calculations using a plane-wave basis set. Phys. Rev. B 54, 11169-11186 (1996).

69. Blöchl, P. E. Projector augmented-wave method. Phys. Rev. B 50, 17953-17979 (1994).

70. Monkhorst, H. J. \& Pack, J. D. Special points for Brillouin-zone integrations. Phys. Rev. B 13, 5188-5192 (1976).

71. Perdew, J. P., Burke, K. \& Ernzerhof, M. Generalized gradient approximation made simple. Phys. Rev. Lett. 77, 3865-3868 (1996).

72. Becke, A. D. Density-functional exchange-energy approximation with correct asymptotic behavior. Phys. Rev. A 38, 3098-3100 (1988).

73. Klimeš, J., Bowler, D. R. \& Michaelides, A. Van der Waals density functionals applied to solids. Phys. Rev. B 83, 195131 (2011).

74. Yoo, H. D., Jang, J. H., Ka, B. H., Rhee, C. K. \& Oh, S. M. Impedance analysis for hydrogen adsorption pseudocapacitance and electrochemically active surface area of Pt electrode. Langmuir 25, 11947-11954 (2009).

75. Farrow, C. L. et al. PDFfit2 and PDFgui: computer programs for studying nanostructure in crystals. J. Phys. Condens. Matter. 19, 335219 (2007).

76. Kraus, W. \& Nolze, G. POWDER CELL-a program for the representation and manipulation of crystal structures and calculation of the resulting X-ray powder patterns. J. Appl. Crystallogr. 29, 301-303 (1996).

77. Nádherná, M., Reiter, J., Moškon, J. \& Dominko, R. Lithium bis(fluorosulfonyl) imide-PYR ${ }_{14}$ TFSI ionic liquid electrolyte compatible with graphite. J. Power Sources 196, 7700-7706 (2011).

\section{Acknowledgements}

Y.Y. acknowledges the financial support from the Office of Naval Research Young Investigator Award (No. N00014-13-1-0543), the National Science Foundation
(CMMI-1400261), the TcSUH core funding, and the University of Houston Start-up Fund. J.L. and S.T.P. acknowledge support from the US Department of Energy (No. DEFG02-09ER46554). S.T.P. also acknowledges support from the Gas Subcommittee Research and Development under Abu Dhabi National Oil Company (ADNOC). X.Q. and H.W. acknowledge the start-up funds from Texas A\&M University, and portions of this research were conducted with the advanced computing resources provided by Texas A\&M High Performance Research Computing. W.Z. acknowledges support by the Department of Energy Office of Science, Basic Energy Sciences, Materials Science and Engineering Directorate. The STEM characterization was supported in part through a user project supported by ORNL's Center for Nanophase Materials Sciences (CNMS), which is sponsored by the Scientific User Facilities Division, Office of Basic Energy Sciences of US Department of Energy. The Advanced Light Source is supported by the Director, Office of Science, Office of Basic Energy Sciences, of the U.S. Department of Energy under Contract No. DE-AC02-05CH11231. Use of the Advanced Photon Source (9-BM and 11-ID) was supported by the U.S. DOE, Office of Basic Energy Sciences, under Contract No. DE-AC0206CH11357.

\section{Author contributions}

H.D.Y. and Y.Y. conceived the concept. H.D.Y. and H.D. conducted electrochemical measurements. J. Lin, W.Z. and S.T.P. conducted STEM and EELS experiments, and analysis. H.W. and X.Q. conducted first-principles calculations. J.G., Y. Liu, L.M., T.W., and $\mathrm{J}$. Lu conducted the $\mathrm{Mg}$ and S K-edge measurements. Y. Li conducted XPS and ICP analysis. Q. R., Y. Li, and H.D. conducted EDS analysis. Y.J., H.D.Y. and Y. Liang conducted NMR analysis. H.D.Y. and Q.A. conducted in operando XRD measurement. Y.Y. supervised the research. H.D.Y., Y. Liang, and Y.Y. co-wrote the paper. All authors discussed the results and commented on the manuscript.

\section{Additional information}

Supplementary Information accompanies this paper at doi:10.1038/s41467-017-00431-9.

Competing interests: The authors declare no competing financial interests.

Reprints and permission information is available online at http://npg.nature.com/ reprintsandpermissions/

Publisher's note: Springer Nature remains neutral with regard to jurisdictional claims in published maps and institutional affiliations.

Open Access This article is licensed under a Creative Commons Attribution 4.0 International License, which permits use, sharing, adaptation, distribution and reproduction in any medium or format, as long as you give appropriate credit to the original author(s) and the source, provide a link to the Creative Commons license, and indicate if changes were made. The images or other third party material in this article are included in the article's Creative Commons license, unless indicated otherwise in a credit line to the material. If material is not included in the article's Creative Commons license and your intended use is not permitted by statutory regulation or exceeds the permitted use, you will need to obtain permission directly from the copyright holder. To view a copy of this license, visit http://creativecommons.org/ licenses/by/4.0\%

(c) The Author(s) 2017 